\title{
ANÁLISE SOBRE AS NOÇÕES DE VIGÊNCIA, VALIDADE E JUSTIÇA: COMPARAÇÕES ENTRE FERRAJOLI E DERRIDÁ
}

\author{
Luize Cristina de Oliveira Alves ${ }^{1}$
}

RESUMO: O objetivo do presente trabalho é analisar de que maneira Luigi Ferrajoli e Jacques Derrida entendem as noções de vigência, validade e justiça das leis, quais os principais pontos de divergência e aproximação entre eles. De antemão, verifica-se que ambos os autores distinguem o mero atendimento a aspectos formais legislativos da real compatibilidade material com o ordenamento jurídico. De igual modo, ambos os autores defendem o que processualmente entende-se como controle difuso, a ser realizado pelos magistrados, porém com objetos de análise distintos. A principal divergência identificada, porém, reside na noção de justiça e na garantia de sua efetividade. Ferrajoli, positivista crítico, realiza a separação entre direito e moral, fundamental para sua teoria e, deste modo, compreende que ideais e princípios de justiça somente servir de parâmetro para o julgamento das leis quando positivados, nos moldes dos constitucionalismos modernos. Para Derrida, por outro lado, a noção de justiça deve servir como parâmetro de análise das leis (se justas ou injustas) a ser realizada pelos juízese, mais que isso, de desconstrução do próprio direito.

Palavras-chave: Vigência. Validade. Justiça. Ferrajoli. Derrida.

ABSTRACT: The aim of this paper is to analyze how Luigi Ferrajoli and Jacques Derrida understand the notions of validity, validity and justice of the laws, which are the main points of divergence and approximation between them. In advance, it appears that both authors distinguish mere compliance with formal legislative aspects from actual material compatibility with the legal system. Similarly, both authors defend what is procedurally understood as diffuse control, to be performed by magistrates, but with distinct objects of analysis. The main divergence identified, however, lies in the notion of justice and the guarantee of its effectiveness. Ferrajoli, a critical positivist, makes the separation of law and morality fundamental to his theory and thus understands that ideals and principles of justice only serve as a parameter for the judgment of laws when positivized, along the lines of modern constitutionalism. For Derrida, on the other hand, the notion of justice should serve as a parameter for analyzing the laws (whether fair or unfair) to be performed by judges and, moreover, for deconstructing their own law.

Keywords: Formal validity. Material validity. Justice. Ferrajoli. Derrida.

Mestranda pelo Programa de Pós-graduação em Direito da Universidade Federal do Pará (PPGD/UFPA). Membro do Grupo de Pesquisa "Garantismo em Movimento" (CNPq) Assessora do Ministério Público do Estado do Pará (MPPA). Bacharel em Direito pela Universidade Federal do Pará (UFPA). E-mail: alves.luize@gmail.com. 


\section{INTRODUÇÃO}

O que se busca comparar neste presente trabalho, ainda que de maneira breve, são as noções de vigência, validade e justiça que Luigi Ferrajoli e Jacques Derrida, enquanto autores contemporâneos ${ }^{2}$ da Teoria do Direito, trabalham.

A divergência entre os autores é evidente. Como sabemos, Ferrajoli é um positivista crítico, legitimador do direito, utilitarista reformado e trabalha com aideia de "garantias" (o que justifica o nome de sua teoria - garantismo jurídico). Derrida, por sua vez, desponta com uma hiperbólica crença na justiça e uma nítida descrença no direito, o que culmina com sua teorização sobre a desconstrução.

As questões centrais de debate são, portanto, a relação entre direito e justiça (e de que modo cada um desses autores percebe esta relação) e a aplicação das leis (perpassando pela noção de autoridade e força, bem comopela ideia de compatibilidade destas com o ordenamento jurídico).

Em suma, a discussão trazida por Derrida parece levitar em torno na seguinte pergunta: como podemos garantir a justiça (que é subjetiva e o que é justo pode variar de caso para caso) por meio das regras (pretensamente) universais, objetivas e generalizantes do direito? ${ }^{3}$ Para Derrida a obediência às leis e a aplicação do direito ocorrem por fatores distintos da ideia de justiça, quais sejam: força e autoridade. Neste sentido, o autor parece nos apresentar uma perspectiva de maior crença na justiça e, por entender como ilegítima a instituição do direito, de desconstrução do jurídico.

Para Ferrajoli, por outro lado, com a secularização do Estado Moderno e a separação entre direito e moral, esta deixa de ser uma preocupação do direito. O direito não tem por função definir o que é justo ou injusto, ou mesmo se orientar dentro destes padrões, esta tarefa cabe à moral. Para Ferrajoli, questõesde justiça social somente tem guarida no direito quando positivadas, no recente fenômeno do (neo)constitucionalismo dos estados modernos. Logo, o caminho apresentado pelo autor parece ser exatamente o oposto ao de Derrida, com um altíssimo nível de crença no direito e considerando a realização da justiça como consequência da correta aplicação do

\footnotetext{
${ }^{2}$ Enquanto "Do direito à justiça" de Jacques Derrida foi proferido em evento realizado no ano de 1989; "Direito e Razão", a primeira obra de Luigi Ferrajoli, foi publicado em 1990.

${ }^{3}$ O que o aproxima das discussões travadas pelo movimento do "Critical Legal Studies" (CLS) acerca da compatibilidade do direito pretensamente universal com a pluralidade de interesses de determinados grupos sociais.
} 
próprio direito.

Por fim, o ponto de convergência que aqui se identifica reside na necessidade, identificada por ambos os autores, de que os juízes realizem o julgamento prévio das leis. Para Derrida, o julgamento deve ser pela justiça ou injustiça das normas e, consequentemente pela sua aplicação ou pela desconstrução do direito. Ferrajoli, por outro lado e mantendo seu posicionamento positivista e legitimador do direito, defende uma análise acercada vigência e da validade.

\section{DO DIREITO À JUSTIÇA: A DESCONSTRUÇÃO DO DIREITO DE JACQUES DERRIDA}

O texto referência de análise das relações supramencionadas é a primeira parte do livro "Força de Lei", intitulada "Do direito à justiça". Trata-se de texto lido na abertura de um colóquio realizado na Cardozo Law School em outubro de 1989, sob organização de Drucilla Cornell.

Ainda do título desta primeira parte do livro depreende-se que, para Derrida, direito e justiça não possuem o mesmo significado, não são expressões sinônimas.

Infere-se ainda que mais do que isso, na maioria das vezes, estas expressões se excluem mutuamente (RODRIGUES, 2007)

Exatamente neste sentido e em momento oportuno, Derrida (2010) esclarece que "se a justiça não é necessariamente o direito ou a lei, ela só pode tornar-se justiça, por direito e em direito, quando detém a força, ou antes quando recorre à força desde seu primeiro instante, sua primeira palavra" (DERRIDA, 2010, p. 17).

Aqui, o autor introduz a noção de força como fundamental para a compreensão do direito. Para Derrida a aplicação do direito e das leis somente é possível por meio de uma força, seja ela justa ou injusta, exercida por autoridade. Assim, o direito é instituído e aplicado por meio da força, não é natural e,portanto, é ilegítimo desde sua origem. Neste momento surgem as bases da teoria da desconstrução.

Logo, não há correspondência direta e pura entre direito e justiça e Derrida afirma que: "A justiça do direito, a justiça como direito não é a justiça. As leis não são justas como leis. Não obedecemos a elas porque são justas, mas porque têm autoridade" (DERRIDA, 20Io, p. 2I). A justiça, segundo Derrida, não é consequência do direito, o justo está para além do jurídico (RODRIGUES, 2007). 
Para Derrida (2010) a questão se torna ainda mais complexa uma vez que esta distinção entre direito e justiça não permanece regulada de maneira lógica; o direito passa a tentar justificar seu exercício com base na justiça e a justiça requer sua instalação em um direito aplicado, posto.

Por fim e para sintetizar a difícil relação entre direito e justiça, Derrida (2010, p. 30) aduz:

\begin{abstract}
A justiça é uma experiência do impossível. Uma vontade, um desejo, uma exigência de justiça cuja estrutura, não fosse uma experiência da aporia, não teria nenhuma chance de ser o que ela é, a saber, apenas um apelo à justiça. Cada vez que as coisas acontecem ou acontecem de modo adequado, cada vez que se aplica tranquilamente uma boa regra a um caso particular, a um exemplo corretamente subsumido, segundo um juízo determinante, o direito é respeitado, mas não podemos ter certeza de que a justiça o foi.
\end{abstract}

O direito não é a justiça. O direito é o elemento do cálculo, é justo que haja um direito, mas a justiça é incalculável, ela exige que se calcule o incalculável; e as experiências aporéticas são experiências tão improváveis quanto necessárias da justiça, isto é, momentos em que a decisão entre o justo e o injusto nunca é garantida por uma regra.

O autor identifica, portanto, o descompasso existente entre a aplicaçãodo direito e a efetivação da justiça, o que conduz para a questão incialmente apontada: é possível eliminar este descompasso? Sendo a justiça algo particular e variável em cada caso, ela pode ser alcançada e efetivada por meio do direito que se propõem a regras gerais e abstratas? Pode o direito variar particularmente? Pode a justiça se generalizar abstratamente? Todas essas são questões que permeiam a difícil relação entre direito e justiça e que justificam a primeira parte do livro "Força de lei" ora sob análise.

O cerne da questão, porém, diz respeito aos critérios de legitimação do direito. Para Derrida, somente a força e a autoridade é que instituem, mantém e fundamentam a aplicação do direito. Não há, portanto, qualquer sustentáculo legítimo da esfera jurídica. A desconstrução trazida por Derrida é, neste sentido, uma constante discussão e desconfiança acerca das origens do direito (BERNARDO, 2009).

A desconstrução inaugura, portanto, novas formas da relação entre direito e justiça. Nas palavras de Oliveira (20II, p. 39):

A questão passa, então, por um conceito que ao mesmo tempo se define dentro e fora do direito, isto é, a justiça. Ela ocupa um espaço na teoria do direito em que as expectativas se reservam. Não basta considera-la um adjetivo para a estrutura jurídica. Derrida pensou a relação entre o direito e a justiça para além da escatologia ou teleologia. Por isso, a desconstrução apresentará outro modo para pensar a justiça em relação ao direito. Não por 
oposição ou complemento, mas na medida em que pode irromper uma diferença de perspectiva e de transformação na construção metafísica do direito.

Entendida a relação que Derrida estabelece entre direito, justiça e desconstrução, cumpre analisar o papel atribuído ao juiz e a aplicação da lei. Em "Força de lei”, Derrida apresenta a construção de seu pensamento por meio de aporias. A primeira delas trata exatamente sobre a relação entre os magistrados, as normas e a justiça. Segundo Derrida (20ı) a liberdade na tomada de decisão por parte dos juízes constitui elemento essencial para alcançar a justiça.

Para Derrida (2010) uma justa decisão por parte de um juiz não pode simplesmente seguir uma regra geral já posta, mas sim, antes de tudo "assumi- la, aprova-la, confirmar seu valor, por um ato de interpretação reinstaurador, como se a lei não existisse anteriormente, como se o juiz a inventasse ele mesmo em cada caso" (DERRIDA, 2010, p. 44).

Derrida (2010) afirma que o exercício da justiça como direito só pode se dar com um julgamento novo, fresco, de caráter inaugural. Defende ainda que, mesmo que com base em uma lei anterior, preexistente, o julgamento deve valer-se de uma capacidade re-inventiva do julgador, livremente decisória. Deve ser, portanto, para Derrida (2010) uma decisão regrada mas sem regras, justa e responsável (no sentido de que assume responsabilidade pela decisão), que conserve a lei mas que seja potencialmente destruidora da lei (e, consequentemente, desconstruidora do direito).

Oliveira (20II) entende que as decisões dos juízes tem força de lei e, justamente por isso, lida com as esferas do calculável (norma) e do incalculável (vida). De tal sorte, segundo Oliveira (2011, p. 83) "a decisão pode gerar cálculo, mas não se origina dele: ela é da ordem do incalculável”.

Deste modo, o Derrida (2010) conclui que:

Cada caso é um caso, cada decisão é diferente e requer uma interpretação absolutamente única, que nenhuma regra existente ou codificada pode nem deve absolutamente garantir. Pelo menos, se ela a garante de modo seguro, então o juiz é uma máquina de calcular; o que às vezes acontece, o que acontece sempre em parte, segundo uma parasitagem irredutível pela mecânica ou pela técnica que introduz a iterabilidade necessária dos julgamentos; mas, nessa medida, não se dirá do juiz que ele é puramente justo, livre e responsável. Mas também não o diremos se ele não se referir a nenhum direito, a nehuma regra ou se, por não considerar nenhuma regra como dada para além de sua interpretação, ele suspender sua decisão, detiver-se no indecidível ou então improvisar, fora de qualquer regra e de qualquer 
princípio. Desse paradoxo decorre que em nenhum momento podemos dizer presentemente que uma decisão é justa, puramente justa (isto é, livre e responsável), nem dizer de alguém que ele é um justo e, ainda menos, que "eu sou justo". No lugar de "justo", podemos dizer legal ou legítimo, em conformidade com um direito, regras ou convenções autorizando um cálculo, mas com um direito cuja autoridade fundadora apenas faz recuar o problema da justiça. Pois no fundamento ou na instituição desse direito o mesmo problema da justiça se colocará, violentamente resolvido, isto é, enterrado, dissimulado, recalcado (DERRIDA, 2010, pp.44-45).

Percebe-se, neste ponto, que Derrida (2010), embora defenda a realização de um exercício de controle judicial da justiça do direito, entende que tal controle é impossível de ser exercido em sua plena eficiência. A justiça permanece, como dito anteriormente, incalculável, inalcançável, como um desafio e objetivo constante a ser perseguido pelo direito.

Ademais, o juiz deve, em cada caso, analisar a aplicação do justo. Derrida defende, portanto, um altíssimo grau de discricionariedade por parte dos juízes. Mas não apenas discricionário, o juiz, para Derrida (2010) deve assumir a responsabilidade pela decisão.

Segundo Oliveira (20II) a tarefa do magistrado é suspender qualquer espécie de cálculo pré-programado para aplicação das normas de modo a deixar transparecer as questões de fundo e os conflitos de interesse por trás da objetividade do processo. Mais ainda Oliveira (2orI) afirma que, para Derrida, deve haver um rompimento com a falácia da imparcialidade, compreendendo que a parcialidade do juiz é sustentada pela autoridade que supostamente o legitima no sistema.

Esta é, pois, a primeira aporia desenhada por Derrida: a de um juizque, para garantir a justiça, deve abandonar a imparcialidade, ser livre para tomar decisões, arcar com a responsabilidade destas e suspender as leis.

\section{VIGÊNCIA, VALIDADE E JUSTIÇA NO POSITIVISMO CRÍTICO DE LUIGI FERRAJOLI}

Para Ferrajoli, por outro lado, da fundamental separação entre direito e moral e entre ser e dever ser, decorrem outras igualmente fundamentais cisões, dentre elas a separação entre justiça e direito. No campo do direito, deve-se analisar tão somente a vigência e a validade das normas, ficando a análise sobre justiça ou injustiça para o âmbito da moral.

Ferrajoli (2002) distingue a mera vigência formal das leis da sua real validade. 
Para o autor, a vigência de uma lei significa tão somente que a sua produção respeitou todos os aspectos formais legais de elaboração, votação e entrada em vigor. Ou seja, para Ferrajoli (2002), a vigência apenas credita à lei seus aspectos formais, sem, portanto, analisar o conteúdo.

A validade ou a validez de uma norma, entretanto, leva em consideração aspectos materiais da lei, analisa o conteúdo da produção legislativa e a sua compatibilidade com o ordenamento jurídico. Frise-se que para Ferrajoli (2002) tal análise não detém-se em questões morais ou de justiça das leis, mas apenas na compatibilidade dos conteúdos legais.

No sentido do acima exposto e em comentário à obra de Ferrajoli, MIGUEL (2009, p. 213) conceitua:

Los términos "vigência" y "validez" vienen a corresponder conceptualmente con la más tradicional distinción entre validez formal y validez material de actos jurídicos como leyes, reglamentos, actosadministrativos, contratos o sentencias: permítaseme simplificar todas essas categorías bajo la idea de norma jurídica. La validez formal, que se há considerado siempre condición necesaria, y bajo ciertas circunstancias también suficiente, para la pertenencia de una norma jurídica a un sistema jurídico, se refiere al cumplimiento de los procedimentos previstos para su aprobación por la autoridad competente. Por su parte, la validez material, que habitualmente se puede intentar constatar mediante un procedimento posterior ao cumplimiento de la anterior forma de validez y que por tanto no se suele considerar sin más como condición necesaria para la pertenencia de la normal al sistema, se refiere a la conformidad de ésta con los contenidosde las normas superiores.

Ferrajoli (2002) chama atenção inclusive para o frequente equívoco de se identificar como "direito válido" o "direito que é” na prática, o que conduz à interpretação de que basta verificar-se a validade formal (vigência) das leis. Nos modernos Estados constitucionais, porém, em que as leis passam a incorporar valores e conteúdos de justiça (a exemplo dos chamados direitos sociais), tal concepção simplista de validade não é suficiente.

Dito de outra forma, os estados modernos, ao incorporarem em seus textos constitucionais (positivando, portanto) conteúdos de caráter social/moral, criam obrigações para que o próprio estado, na figura dos três poderes, realize tais ideais.

Em resumo, Ferrajoli (2002, pp. 287-288) entende que:

Esta concepção exclusivamente formal de validade certamente resulta adequada se referida a ordenamentos jurídicos de estrutura elementar nos 
quais o legislador é legibus solutus, de forma que qualquer norma dele emanada e da maneira que ele queira é uma norma válida. Contrariamente, nos modernos Estados constitucionais de direito, nos quais a validade das normas - assim como das leis, dos regulamentos, sentenças e atos administrativos reside na sua correspondência não somente formal como também material com as normas de categoria superior, que não só regulam as formas senão que estabelecem também limitações de conteúdo ao exercício do poder normativo, tal concepção resulta totalmente insuficiente. (...)

De fato tem acontecido, na formação dos modernos estados constitucionais, que o direito positivo tem incorporado grande parte dos conteúdos ou valores de justiça elaborados pelo jusnaturalismo racionalista e iluminista (...). Todos esses princípios, afirmados pelas doutrinas jusnaturalistas dos séculos XVII e XVIII na forma de direito ou de direitos naturais, foram consagrados nas modernas constituições na forma de princípios normativos fundamentais que contêm limitações ou imperativos negativos - ou também positivos, como os expressados pelos chamados "direitos sociais" ou "materiais" (ao trabalho, à saúde, à subsistência, à educação etc.), acrescentados nas constituições deste século -, cujos destinatários são os legisladores e os demais poderes públicos.

Logo, para o autor, a incorporação de valores de justiça e de princípios originalmente intitulados como "direitos naturais" nas constituições do estado moderno é um fenômeno que passa a sujeitar todos os poderes públicos (incluindo principalmente, no tema em análise, o legislativo) às leis superiores (constitucionais) que passam a positivar tais princípios e valores.

Ainda nestas questões acerca da vigência e da validade das leis e paraintroduzir a noção de justiça, Ferrajoli, em outra obra, aduz:

La primera transformación - en la estructura del sistema jurídico - se produjo con la invención y la introducción, sobre todo después de la segunda guerra mundial, de las constituciones rígidas, que incorporan princípios y derechos fundamentales como límites y vínculos ya no sólo al poder ejecutivo y judicial, sino también al poder legislativo.

(...)

Se trata de un cambio radical de paradigma del derecho moderno: una suerte de segunda revolución que cambia al mismo tempo la natureza del derecho, la natureza de la política y la natureza de la democracia. Enel plano de la teoría del derecho este cambio puede expresarse mediante la tesis de la subordinación de la propia ley al derecho y de la consiguiente disociación de vigência (o existencia) y validez de las normas. La primera revolución en la historia de la modernidad jurídica, la que tuvo lugar con el nacimiento del derecho moderno, se había expresado con la afirmación del principio de legalidad y, com él, de la omnipotência del legislador. Así, se conseguía, en oposicíon a las viejas concepciones iusnaturalistas, la identificación de la validez de las leyes con su positividad, es decir, con su emanación en las formas previstas por el ordenamento. Auctoritas, non veritas facit legem, declaró Hobbes en el Diálogo entre un filósofo y un jurista, invirtiendo la vieja máxima iusnaturalista veritas, non auctoritas facit legem: el derecho no es lo ontologicamente verdadero o justo, sea cual fuere lo que se entienda con estas expresiones, sino lo convenido como tal por la ley (FERRAJOLI, 2010, pp. 209-210). 
Ou seja, para Ferrajoli (2008) a partir da separação fundamental entre direito e moral, o direito não pode ser entendido como o justo ou verdadeiro, mas tão somente aquilo que está positivado em leis não apenas vigentes (aspectos formais de elaboração e promulgação) mas também válidas (quando analisadas em seus conteúdos e a compatibilidade destes com o ordenamento jurídico).

É dizer: valores morais e/ou de justiça, para o positivismo jurídico, não pertencem ao direito. Como visto, uma vez positivados e, somente a partir desta fundamentação, eles passam a ser exigíveis dos poderes estatais.

Como positivista crítico, Ferrajoli é um legitimador do direito e, portanto, completamente contrário aos ideais abolicionistas ou desconstrutivistas. Justifica o direito inclusive em mais de um nível (justificação interna e justificação externa) de modo que, superadas as verificações de vigência e validade acima expostas, reconhece a legitimidade das normas jurídicas.

Por fim, ainda sobre a relação entre direito e justiça, Ferrajoli (2002, p. 296) disserta:

Pode-se dizer, inclusive, que quanto mais altos e ambiciosos são os valores de justiça professados e perseguidos por um ordenamento, e quanto mais complexas e vinculantes são as garantias incorporadas para tal fim em seus níveis normativos superiores, mais ampla é a possível divergência entre modelos normativos e práticas efetivas e, por conseguinte, o índice de ineficácia das primeira e da falta de validez das segundas (...)

A divergência estrutural entre validade e vigência, ou entre níveis normativos superiores e níveis normativos inferiores, ou entre o dever ser e o ser no direito, constitui o principal objeto de investigação de uma teoria garantista e analítica do direito penal ${ }^{4}$, da mesma forma que a divergência entre justiça e validade, ou entre ponto de vista político externo e ponto de vista jurídico interno, ou entre dever ser e ser do direito constitui o objeto privilegiado de uma filosofia analítica da justiça penal. Podemos chamar de uma justiça interna (ou legal) a correspondência entre vigência e validade no seio de cada ordenamento: das leis em relação à Constituição e das sentenças em relação às leis; e podemos chamar de justiça externa à correspondência entre validade e justiça, quer dizer, a adesão do ordenamento em seu conjunto a valores políticos externos. Devido ao caráter estrutural de ambas as divergências, caberia falar, obviamente apenas de graus de justiça tanto externa quanto interna. O grau de justiça externa se mede pela quantidade e qualidade dos princípios de justiça incorporados limitativamente nos níveis normativos mais altos do ordenamento; o graude justiça interna depende da quantidade e qualidade das garantias das quais esteja dotado o ordenamento, ou seja, das técnicas institucionais capazes de assegurar a máxima correspondência entre normatividade e efetividade dos princípios incorporados.

\footnotetext{
${ }^{4} \mathrm{Na}$ obra "Direito e razão" Ferrajoli utiliza o campo do Direito Penal como um campo fértil para análise de sua teoria do garantismo jurídico para só ao final do livro expandir os significados paraas demais áreas e, com isso, estabelecer o garantismo dentro da Teoria do Direito.
} 
Para Ferrajoli (2002) existem, portanto, graus de justiça e graus de garantismo que se correspondem. De maneira simplificada pode-se dizer que quanto mais garantias possuir um dado ordenamento jurídico (ou seja, quanto mais positivados estiverem os direitos) maior a possibilidade de se efetivar ajustiça.

Isto porque, para Ferrajoli (2002), quanto mais precisa forem as normas, mais restrito estará o poder. $\mathrm{O}$ autor não nega que sempre haverá uma margem irredutível de discricionariedade, mas afirma que, quanto menor for esta margem, menores serão os arbítrios e abusos de poder e, via de consequência, mais perto estaremos de garantir a justiça.

Desta forma, Ferrajoli (2002) defende que o juízes devem sim terliberdade para julgar, mas apenas no que diz respeito a vigência e validade das leis e a mínima margem de discricionariedade supramencionada. Não cabe aos juízes, na visão do positivista critico, tecer julgamentos acerca da justiça das normas.

A suspensão da aplicação de uma dada lei para Ferrajoli (2002) somente é possível quando maculadas a sua vigência e/ou validade. Nestes casos, segundo o autor, deve o juiz ter liberdade suficiente para afastar a aplicação de uma norma cuja vigência ou validade estejam viciadas.

É, portanto, este grau de liberdade que Ferrajoli (2002) atribui como devido aos magistrados. Qualquer outra margem de discricionariedade está, em atenção à teoria do garantismo jurídico proposta por Ferrajoli, tendendo ao abusode poder.

\section{CONCLUSÃO}

Os textos principais analisados ${ }^{5}$ são contemporâneos e traduzem angustias frequentes no âmbito da teoria do direito. Como visto, ambos os autores possuem profunda preocupação com as noções de vigência e validade das leis e, mais do que isso, com a relação entre justiça e direito. Os caminhos para efetivar a justiça e o local que ela ocupa nesta relação com o direito é que são o principal ponto de divergência.

Para Derrida, a justiça deve servir como parâmetro de análise dos casos específicos pelos juízes. $\mathrm{O}$ autor defende que direito e justiça não possuem o mesmo significado, sendo por vezes excludentes. Para Derrida, o juízes devem perseguir a

\footnotetext{
5 Conforme já supramencionado, "Direito e razão" (Luigi Ferrajoli, 199o) e "Força de lei" (Jacques Derrida, 1989).
} 
justiça e avalia-la a cada caso, ainda que, para isso, resultem em alto grau de discricionariedade em relação as regras objetivas e gerais do direito, inclusive suspendendo-as quando necessário (desconstrução do direito).

A discricionariedade não é vista por Derrida como um problema, mas sim como a única maneira de se efetivar a justiça por meio do direito. $O$ autor defende que os juízes devem gozar de plena liberdade e livre arbítrio nas suas decisões para que assim seja dado o primeiro passo para alcançar a justiça.

Derrida observa ainda que é impossível falar em decisões totalmente justas por parte dos juízes e reconhece que a justiça da decisão perpassa pela responsabilidade do julgador. Esta é, portanto, a primeira aporia trabalhada por Derrida.

De outra sorte, Ferrajoli, positivista critico, ao defender a separação entre moral e direito e entre ser e dever ser, conduz à separação também entre direito e justiça. Não nega que exista uma relação entre os conceitos, mas o ser do direito não necessariamente é justo. Para Ferrajoli, o que há, portanto, são graus de justiça e a estreita vinculação ao direito positivo e às garantias positivadas é que conduz a um maior grau de justiça.

Ferrajoli traz outra separação fundamental para sua teoria: entre vigência e validade. Para o autor, controle a ser realizado pelos julgadores nos casos concretos deve ser acerca da compatibilidade ou incompatibilidade da norma com o ordenamento jurídico, tanto em forma (vigência) quanto em conteúdo (validade).

Para Ferrajoli, portanto, a justiça não é parâmetro de análise do juiz no caso concreto, mas consequência da positivação de direitos, devendo ser analisada tão somente a lei e sua validade. Assim, Ferrajoli é completamente contrário à discricionariedade dos juízes, acredita no direito posto, na precisão semântica e nas garantias estabelecidas. Ferrajoli, ao contrário de Derrida, não acredita na figura do bom juiz ou do juiz responsável. Para o autor, a noção de justiça está intimamente ligada às garantias.

Conclui-se, portanto, que os autores se aproximam nas preocupações acerca da relação entre direito e justiça, no consenso de que estas são categorias distintas e de que uma não é consequência direta da outra e, até mesmo, na necessidade de uma espécie de controle judicial difuso.

Divergem, porém, quanto a forma de efetivação da justiça: Derrida acredita que 
esta deve se ocorrer por meio da discricionariedade dos juízes, com elevada liberdade de decisão e a partir da suspensão das normas e da desconstrução do direito; enquanto que Ferrajoli defende a estrita positivação de garantias, com precisão semântica e admitindo o mínimo possível de discricionariedade, com "liberdades" apenas para o controle de vigência e validade.

\section{REFERÊNCIAS}

BERNARDO, Fernanda. A crença de Derrida na justiça: para além do direito, a justiça. In: Ágora. vol. 28. n. 02, 2009, pp. 53-94. Disponível em: https://minerva.usc.es/xmlui/handle/10347/7356. Acessado em: 12/12/2019.

DERRIDA, Jacques. Força de lei: o fundamento místico da autoridade. za ed. São Paulo: Editora WMF Martins Fontes, 2010.

FERRAJOLI, Luigi. Democracia y Garantismo. Madrid: Editorial Trotta, 2008.

FERRAJOLI, Luigi. Direito e Razão: teoria do garantismo penal. São Paulo: Editora Revista dos Tribunais, 2002.

MIGUEL, Alfonso Ruiz. Validez y vigência: un cruce de caminhos en el modelo garantista. In: Garantismo: estúdios sobre el pensamiento jurídico de Luigi Ferrajoli. 2a ed. Madrid: Editorial Trotta, 2009.

OLIVEIRA, Manoel Carlos Uchôa de. Desconstrução e direito: uma leitura sobre "Força de lei" de Jacques Derrida, 20II. Disponível em: https://repositorio.ufpe.br/handle/123456789/4770. Acessado em: 03/12/2019.

RODRIGUES, Carla. Justiça, direito e emancipação. Revista de Estudos Feministas.Florianópolis, v. 15, n. 2, pp. 491-493, 2007 . Disponível em: http://www.scielo.br/scielo.php?script=sci_arttext\&pid=Soro4- nrm=iso. Acessado em: 03/12/2019. 